\title{
HRJ
}

\author{
v.3 n.14 (2022) \\ Recebido: 29/11/2021
}

Aceito: 04/01/2022

\section{Enfermagem no contexto da infecção da ferida cirúrgica: revisão integrativa}

\section{Marcos Vinícius Santos da Câmara ${ }^{1}$ Caroline Almeida Felix ${ }^{2}$ Marcelo Moreira Corgozinho ${ }^{3}$}

\footnotetext{
${ }^{1}$ Enfermeiro do Programa de Residência Uniprofissional de Enfermagem em Centro Cirúrgico da ESCS/Fepecs. E-mail: mv.camara00@gmail.com

${ }^{2}$ Preceptora do Programa de Residência Uniprofissional de Enfermagem em Centro Cirúrgico da ESCS/Fepecs. Especialista em Enfermagem de Centro Cirúrgico. E-mail: 87.felix@gmail.com

${ }^{3}$ Tutor e Preceptor do Programa de Residência Uniprofissional de Enfermagem em Centro Cirúrgico ESCS/Fepecs. Doutor pela Faculdade de Saúde da Universidade de Brasília. E-mail: mmcorgozinho@gmail.com
}

\section{RESUMO}

Objetivo: O presente artigo objetiva descrever o perfil teórico das publicações sobre a enfermagem no contexto da infecção da ferida cirúrgica. Método: trata-se de revisão integrativa da literatura entre 2016 e 2021, nas bases de dados SciELO, Lilacs e Medline , a partir dos Descritores Ciências da Saúde "infecção de ferida cirúrgica" and "infecção de sítio cirúrgico" and "enfermagem". Resultados: foram eleitas três categorias temáticas para a discussão, a saber: infecção de sitio cirúrgico; enfermagem e as diretrizes para a prevenção da infecção de sítio cirúrgico; e enfermagem no contexto da infecção da ferida cirúrgica. Conclusão: a prevenção da infecção requer uma abordagem multifatorial, sendo que o enfermeiro é considerado o profissional-chave no manejo de cuidados perioperatório necessários para minimizar os riscos de infecção. Os profissionais da saúde devem estar atentos às diretrizes atualizadas para a prevenção e manejo das infecções da ferida cirúrgica.

Palavras-chave: Infecção de Ferida Cirúrgica, Enfermagem Perioperatória, Centros Cirúrgicos.

\section{Nursing in the context of surgical wound infection: integrative review}

\begin{abstract}
Objective: This article aims to describe the theoretical profile of publications on nursing in the context of surgical wound infection. Method: this is an integrative literature review between 2016 and 2021, in the SciELO, Lilacs and Medline databases - from the Health Sciences Descriptors "surgical wound infection" and "surgical site infection" and "nursing". Results: three thematic axes were chosen for the discussion, namely: surgical site infection; nursing and guidelines for the prevention of surgical site infection; and nursing in the context of surgical wound infection. Conclusion: the prevention of infection requires a multifactorial approach, and the nurse is considered the key professional in managing the perioperative care necessary to minimize the risk of infection. Health professionals should be aware of updated guidelines for the prevention and management of surgical wound infections.
\end{abstract}

Keywords: Surgical Wound Infection, Perioperative Nursing, Surgical Centers. 


\section{INTRODUÇÃO}

A qualidade e segurança do cuidado perioperatório relaciona-se diretamente ao desenvolvimento de modelos tecno-assistenciais, os quais se constituem em verdadeiros desafios para as organizações de saúde, em virtude da crescente evolução tecnológica aliada à incorporação de novos processos clínicos e técnicas cirúrgicas. Tais avanços, apesar de contribuírem para a maior qualidade dos serviços prestados representam, ao mesmo tempo, riscos assistenciais agravados por falhas estruturais do sistema ou devido à deficiência na gestão dos processos de trabalho, podendo culminar em eventos adversos em pacientes submetidos ao tratamento cirúrgico ${ }^{1}$.

No mundo, aproximadamente 4.511 operações por 100.000 habitantes ocorrem anualmente, o que equivale a um procedimento cirúrgico para cada 22 pessoas $^{2}$. As infecções hospitalares são consideradas um grande problema de saúde por afetar, todos os anos, um elevado número de pessoas no mundo ${ }^{3}$. Em países industrializados as complicações relacionadas aos procedimentos cirúrgicos são registradas entre 3\% e $16 \%$ dos pacientes, ao passo que nos países em desenvolvimento, a mortalidade ocasionada por tais complicações oscila entre 5 e $10 \%$ dos pacientes ${ }^{4}$.

Estudos têm demonstrado que entre os eventos adversos mais comuns ocorridos na área da saúde estão os relacionados às infecções de feridas cirúrgicas, às quais também se constituem nas principais responsáveis pelas chamadas Infecções de Sítio Cirúrgico (ISC) 5 . As ISC dizem respeito à infecção que ocorre no local do procedimento cirúrgico, estando relacionada a uma complicação local da região cirúrgica. No Brasil, às chamadas Infecções Relacionadas com a Assistência à Saúde (IRAS), abrangem de 14 a 16\% das hospitalizações ${ }^{6}$.

A prevenção da ISC envolve uma ampla abordagem, e o enfermeiro deve participar com rigor em todas as fases do procedimento cirúrgico - é o profissional protagonista na elaboração e implementação de medidas que resultam positivamente em um atendimento 
eficaz para a recuperação do paciente na prevenção de riscos advindos de procedimentos cirúrgicos $^{6}$. Nesse sentido, no momento da cirurgia os pacientes necessitam de atenção, cuidado e orientações específicas devido aos sentimentos como ansiedade, medo, angústia e dúvidas, de forma que a equipe de enfermagem se constitui nos profissionais capazes de fornecer os cuidados e orientações específicas nestas situações ${ }^{7}$.

A escolha deste tema justifica-se em virtude de as feridas cirúrgicas constituírem os tipos de feridas mais comumente tratadas em ambientes de cuidados críticos, bem como pelo fato de os enfermeiros serem quem geralmente lideram as equipes interprofissionais de saúde - tomando decisões de enfermagem ou recomendando a outros profissionais a respeito de várias intervenções para o correto gerenciamento de feridas cirúrgicas ${ }^{2}$. Portanto, este estudo objetiva descrever, a partir da literatura, o perfil teórico das publicações sobre a enfermagem no contexto da infecção da ferida cirúrgica.

\section{METODOLOGIA}

Trata-se de uma revisão integrativa da literatura que seguiu as etapas adaptadas das recomendações do Preferred Reporting Items for Systematic Reviews and Meta-Analyses (Prisma $^{8}$. A questão norteadora para seleção dos textos foi "qual o perfil teórico das publicações que versam sobre o papel da enfermagem no contexto na infecção da ferida cirúrgica?". Nesse sentido, foram definidos os parâmetros: população (paciente cirúrgico), interesse do estudo (infecção da ferida cirúrgica), contexto (sem comparação) e desfecho (perfil teórico sobre enfermagem na infecção da ferida cirúrgica).

\section{Critérios de elegibilidade}

Para a construção do referencial teórico desta pesquisa foram incluídos artigos científicos publicados entre 2016 e 2021 (5 anos), sobre o contexto da enfermagem na infecção da ferida cirúrgica. Consideraram-se elegíveis os textos que, obrigatoriamente, 
tratavam do contexto da enfermagem na infecção de sítio cirúrgico nos títulos, resumos e palavras-chave. Foram excluídos os protocolos de pesquisa, editoriais, textos indisponíveis na íntegra, dissertações e teses.

\section{Estratégia de busca bibliográfica}

Realizou-se levantamento bibliográfico nas seguintes bases de dados Scientific Electronic Library Online (SciELO), Literatura Latino-americana e do Caribe em Ciências da Saúde (Lilacs), US National Library of Medicine (Medline) - com os Descritores em Ciências da Saúde (DeCS) “infecção de ferida cirúrgica" and "infecção de sítio cirúrgico" and "enfermagem" e no Medline os termos em inglês "surgical wound infection" and "surgical site infection" and "nursing". A utilização dos descritores aconteceu de forma controlada nos portais das bibliotecas supramencionadas, de modo a recuperar artigos com texto completo nos últimos cinco anos, nos idiomas português, espanhol e inglês. Na Figura 1, segue o fluxo de seleção dos textos:

Figura 1 - Processo de seleção dos artigos

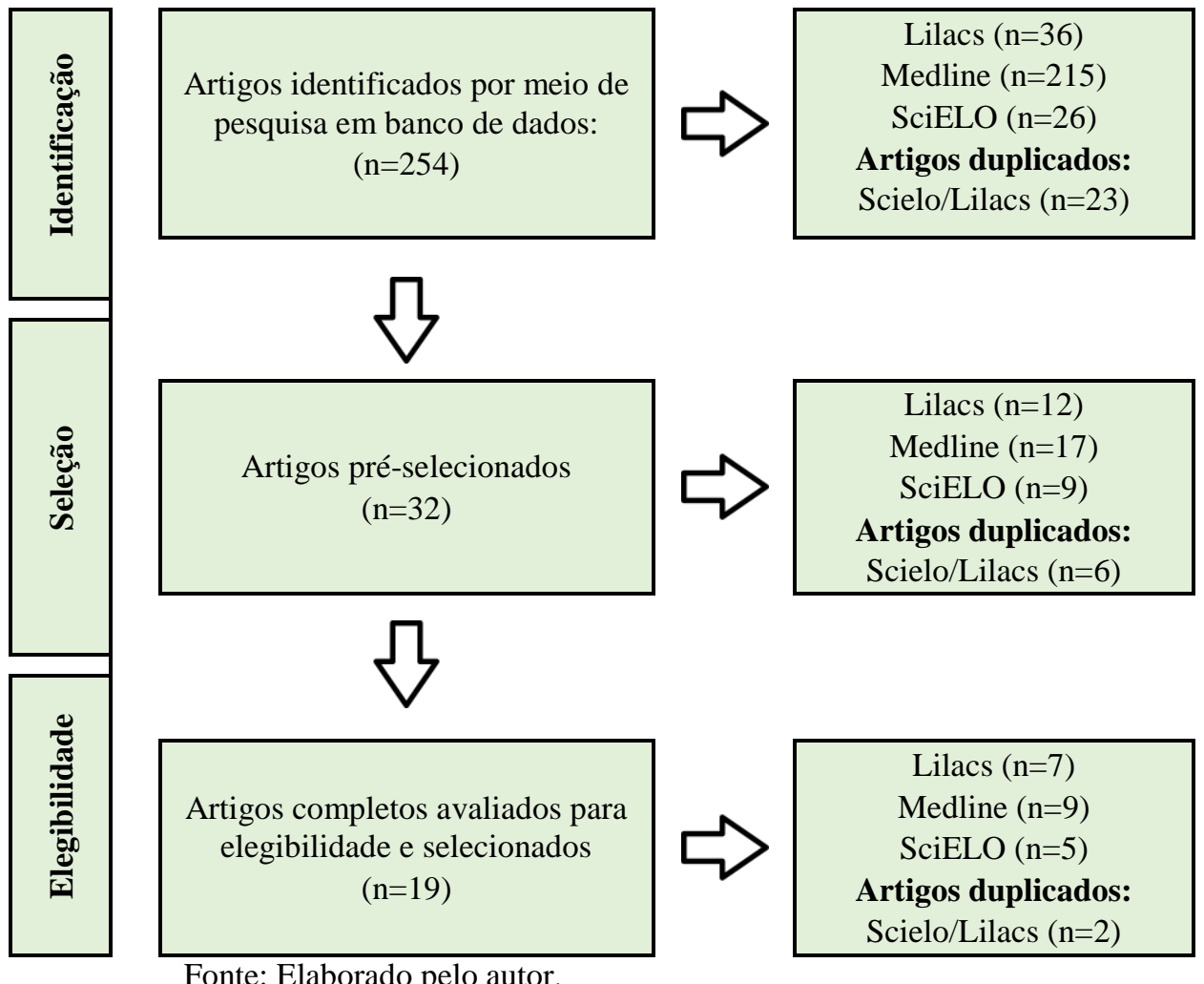

Fonte: Elaborado pelo autor. 


\section{Seleção e avaliação da qualidade dos estudos}

A seleção dos artigos para compor o referencial teórico exigiu leitura e análise minuciosa de todo material coletado. Conforme a Figura 1, inicialmente identificaram-se 277 artigos - 36, Lilacs; 215, Medline; e 26, Scielo (23 duplicados nas bases Scielo e Lilacs), resultando em 254 textos. Após análise e exclusão de publicações, prosseguiu-se com a triagem dos artigos por meio da leitura dos títulos, resumos e palavras-chave restando 38 artigos - 12, Lilacs; 17, Medline; e 9, Scielo (06 duplicados nas bases Scielo e Lilacs) resultando em 32 artigos. Posteriormente, a partir da leitura do texto na íntegra excluindo-se aqueles que não respondiam à questão norteadora deste estudo (exclusão de 13 artigos). Assim, elegeu-se a amostra de 19 artigos para a composição do referencial teórico - 7, Lilacs; 9, Medline; e 5, Scielo (02 duplicados nas bases Scielo e Lilacs.

\section{RESULTADOS E DISCUSSÃO}

A fim de facilitar a coleta de informações foi elaborado um quadro (Quadro 1) com os seguintes dados: características (título do artigo, base de dados, periódico), objetivo do estudo e principais resultados e/o contribuições dos dezenove artigos selecionados. Ao final, realizou-se a análise crítica e categorização temática para a composição do corpus desta pesquisa, a saber: infecção de sitio cirúrgico; enfermagem e as diretrizes para a prevenção da infecção de sítio cirúrgico; e enfermagem no contexto da infecção da ferida cirúrgica.

\section{Quadro 1. Descrição dos artigos incluídos - enfermagem no contexto da ISC}

\begin{tabular}{|c|c|c|c|c|}
\hline Títulos dos Estudos & $\begin{array}{c}\text { Base de } \\
\text { Dados }\end{array}$ & $\begin{array}{c}\text { Periódico } \\
\text { Ano }\end{array}$ & Objetivo & Principais resultados \\
\hline $\begin{array}{l}\text { 1. The nurses' role in the } \\
\text { diagnosis and surveillance } \\
\text { of orthopaedic surgical } \\
\text { site infections. }\end{array}$ & Medline & $\begin{array}{l}\text { Internation } \\
\text { al Journal } \\
\text { of } \\
\text { Orthopaed } \\
\text { ic and } \\
\text { Trauma } \\
\text { Nursing }\end{array}$ & $\begin{array}{l}\text { Fornecer uma visão } \\
\text { geral das melhores } \\
\text { práticas no } \\
\text { diagnóstico de ISC } \\
\text { após cirurgia } \\
\text { ortopédica e delinear } \\
\text { o papel da }\end{array}$ & $\begin{array}{l}\text { O reconhecimento precoce da infecção da } \\
\text { ferida é central no tratamento imediato e } \\
\text { fazem parte do processo de vigilância da } \\
\text { infecção da ferida. Para desempenhar este } \\
\text { papel de forma eficaz, os enfermeiros } \\
\text { precisam compreender como reconhecer } \\
\text { com precisão a infecção da ferida, bem }\end{array}$ \\
\hline
\end{tabular}




\begin{tabular}{|c|c|c|c|c|}
\hline & & 2021 & $\begin{array}{l}\text { enfermagem na } \\
\text { vigilância de ISC. }\end{array}$ & $\begin{array}{l}\text { como seu papel na vigilância da infecção } \\
\text { da ferida. }\end{array}$ \\
\hline $\begin{array}{l}\text { 2. Fatores de risco para } \\
\text { infecção de sítio cirúrgico } \\
\text { em cirurgias traumato- } \\
\text { ortopédicas. }^{10}\end{array}$ & Lilacs & $\begin{array}{c}\text { Revista } \\
\text { Cuidarte } \\
2021\end{array}$ & $\begin{array}{c}\text { Verificar a } \\
\text { associação entre os } \\
\text { fatores de risco e a } \\
\text { presença de Infecção } \\
\text { de Sítio Cirúrgico em } \\
\text { cirurgias traumato- } \\
\text { ortopédicas. }\end{array}$ & $\begin{array}{l}\text { Das variáveis estudadas, comportaram-se } \\
\text { como fatores de risco de Infecção de Sítio } \\
\text { Cirúrgico: tabagismo, diabetes e idade } \\
\text { acima de } 50 \text { anos. A idade foi o principal } \\
\text { fator de risco relacionado ao paciente, } \\
\text { presente em } 31,36,9 \% \text { dos casos. Dor, } \\
\text { edema e hiperemia foram os sinais de } \\
\text { infecção mais prevalentes. }\end{array}$ \\
\hline $\begin{array}{l}\text { 3. Eficacia de un modelo } \\
\text { de prevención de } \\
\text { infección de sitio } \\
\text { quirúrgico en un hospital } \\
\text { de segundo nivel de } \\
\text { tención. }\end{array}$ & Scielo & $\begin{array}{l}\text { Index } \\
\text { Enferm } \\
2020\end{array}$ & $\begin{array}{l}\text { Avaliar a eficácia de } \\
\text { um modelo } \\
\text { preventivo de ISC } \\
\text { em um hospital de } \\
\text { atenção de segundo } \\
\text { nível em Nuevo } \\
\text { León, México. }\end{array}$ & $\begin{array}{l}\text { Foi possível reduzir a taxa de infecções } \\
\text { cirúrgicas em torno de } 3 \% \text {, diminuindo } \\
\text { consideravelmente o número de casos em } \\
\text { relação ao período anterior semelhante do } \\
\text { estudo. }\end{array}$ \\
\hline $\begin{array}{l}\text { 4. Preoperative and } \\
\text { postoperative } \\
\text { recommendations to } \\
\text { surgical wound care } \\
\text { interventions: a systematic } \\
\text { meta-review of Cochrane } \\
\text { reviews. }\end{array}$ & Medline & $\begin{array}{l}\text { Internation } \\
\text { al Journal } \\
\text { of Nursing } \\
\text { Studies. } \\
2020\end{array}$ & $\begin{array}{l}\text { Sintetizar e avaliar as } \\
\text { recomendações para } \\
\text { a prática e pesquisa } \\
\text { de enfermagem de } \\
\text { revisões sistemáticas } \\
\text { publicadas na } \\
\text { Biblioteca Cochrane } \\
\text { sobre profilaxia pré- } \\
\text { operatória conduzida } \\
\text { por enfermeiros. }\end{array}$ & $\begin{array}{l}\text { Vinte e duas revisões Cochrane } \\
\text { preencheram os critérios de inclusão. } \\
\text { Desses, onde revisões enfocaram } \\
\text { intervenções pré-operatórias para prevenir } \\
\text { infecça, enquanto doze enfocaram } \\
\text { intervenções pós-operatórias (uma revisão } \\
\text { avaliou ambas as intervenções pré- } \\
\text { operatórias). Em todas as revisões fizeram } \\
\text { pelo menos uma das recomendações. }\end{array}$ \\
\hline $\begin{array}{l}\text { 5. Ações de enfermagem } \\
\text { podem prevenir } \\
\text { deiscência em ferida } \\
\text { operatória? }^{12}\end{array}$ & Lilacs & $\begin{array}{l}\text { Rev } \\
\text { Sobecc } \\
2020\end{array}$ & $\begin{array}{c}\text { Identificar na } \\
\text { literatura } \\
\text { intervenções de } \\
\text { enfermagem úteis } \\
\text { para a prevenção de } \\
\text { deiscências em } \\
\text { feridas cirúrgicas. }\end{array}$ & $\begin{array}{l}\text { Houve pouca produção da enfermagem } \\
\text { sobre o tema. As principais ações de } \\
\text { enfermagem para prevenção de deiscência } \\
\text { em feridas cirúrgicas estão associadas à } \\
\text { prevenção de ISC e a indicação da } \\
\text { utilização de terapia de cobertura a vácuo. }\end{array}$ \\
\hline $\begin{array}{l}\text { 6. Post-discharge } \\
\text { surveillance of surgical } \\
\text { site infections in teaching } \\
\text { hospitals in Brazil. }^{13}\end{array}$ & $\begin{array}{l}\text { Lilacs } \\
\text { Scielo }\end{array}$ & $\begin{array}{l}\text { Rev Esc } \\
\text { Enferm } \\
\text { USP } \\
2020 \text {. }\end{array}$ & $\begin{array}{l}\text { Compreender a } \\
\text { realidade da } \\
\text { vigilância pós-alta de } \\
\text { infecções de sítio } \\
\text { cirúrgico em } \\
\text { hospitais } \\
\text { universitários } \\
\text { brasileiros. }\end{array}$ & $\begin{array}{l}\text { Dos } 193 \text { hospitais universitários no Brasil, } \\
\text { somente } 149 \text { aceitaram participar - } 96 \% \\
\text { das instituições realizaram vigilância de } \\
\text { ISC durante a hospitalização; } 29,3 \% \text {, a } \\
\text { busca ativa; e } 84 \% \text {, realizavam vigilância } \\
\text { pós-alta principalmente por telefone. } \\
\text { Ambas as ações de vigilância têm o } \\
\text { enfermeiro como principal responsável. }\end{array}$ \\
\hline $\begin{array}{l}\text { 7. Saberes dos } \\
\text { enfermeiros sobre } \\
\text { prevenção de infecções do } \\
\text { sítio cirúrgico. }^{14}\end{array}$ & Lilacs & $\begin{array}{l}\text { Rev. } \\
\text { Sobecc. } \\
2020\end{array}$ & $\begin{array}{l}\text { Conhecer as } \\
\text { experiências de } \\
\text { enfermeiros sobre } \\
\text { suas práticas na } \\
\text { prevenção ISC. }\end{array}$ & $\begin{array}{l}\text { Observou-se preocupação em minimizar } \\
\text { os riscos de ISC por meio da adoção de } \\
\text { ações preventivas, como lavagem das } \\
\text { mãos, uso de equipamentos de proteção } \\
\text { individual, troca de curativos diários com } \\
\text { técnica asséptica e uso de insumos } \\
\text { adequados, conhecimento técnico- } \\
\text { científico harmonioso e estímulo do } \\
\text { relacionamento eficaz entre a equipe. }\end{array}$ \\
\hline $\begin{array}{l}\text { 8. Perioperative strategies } \\
\text { for surgical site infection } \\
\text { prevention. }{ }^{15}\end{array}$ & Medline & $\begin{array}{c}\text { AORN } \\
\text { Journal. } \\
2019\end{array}$ & $\begin{array}{l}\text { Explorar as causas } \\
\text { das ISC, como os } \\
\text { fatores intrínsecos e } \\
\text { extrínsecos, como } \\
\text { aqueles relacionados } \\
\text { ao procedimento pré, } \\
\text { intra e pós- } \\
\text { operatórios. }\end{array}$ & $\begin{array}{l}\text { As ISC são prejudiciais à saúde, ao bem } \\
\text { estar dos pacientes e das instituições de } \\
\text { saúde. Sua prevenção é uma parte } \\
\text { importante da prática de enfermagem } \\
\text { perioperatória. Cada membro da equipe } \\
\text { cirúrgica tem a responsabilidade com o } \\
\text { paciente de seguir as práticas baseadas em } \\
\text { evidências para prevenir as ISC. }\end{array}$ \\
\hline $\begin{array}{l}\text { 9. Link, T. Guideline } \\
\text { implementation: } \\
\text { transmission-based } \\
\text { precautions. }{ }^{16}\end{array}$ & Medline & $\begin{array}{c}\text { AORN } \\
2019\end{array}$ & $\begin{array}{l}\text { Descrever as } \\
\text { precauções padrão } \\
\text { para prevenir a } \\
\text { transmissão de }\end{array}$ & $\begin{array}{l}\text { As intervenções mais importantes para } \\
\text { prevenir a transmissão da infecção são a } \\
\text { higiene das mãos e o uso de precauções } \\
\text { padrão para todos os pacientes. Outras }\end{array}$ \\
\hline
\end{tabular}




\begin{tabular}{|c|c|c|c|c|}
\hline & & & $\begin{array}{l}\text { infecções, descrever } \\
\text { as precauções de } \\
\text { contato e o uso de } \\
\text { equipamentos de } \\
\text { proteção individual } \\
\text { para prevenção de } \\
\text { infecçôes. } \\
\end{array}$ & $\begin{array}{l}\text { precauções são baseadas em como um } \\
\text { organismo é transmitido; isso inclui } \\
\text { precauções de contato, transporte aéreo e } \\
\text { gotículas. }\end{array}$ \\
\hline $\begin{array}{l}\text { 10. Intraoperative } \\
\text { prevention of Surgical } \\
\text { Site Infections as } \\
\text { experienced by operating } \\
\text { room nurses. }{ }^{17}\end{array}$ & Medline & $\begin{array}{l}\text { Internation } \\
\text { al Journal } \\
\quad \text { of } \\
\text { Qualitative } \\
\text { Studies on } \\
\text { Health and } \\
\text { Well- } \\
\text { being } \\
2019\end{array}$ & $\begin{array}{l}\text { Examina como os } \\
\text { enfermeiros do } \\
\text { centro cirúrgico } \\
\text { vivenciam a } \\
\text { prevenção } \\
\text { intraoperatória de } \\
\text { ISC. }\end{array}$ & $\begin{array}{l}\text { A prevenção de ISC requer um trabalho de } \\
\text { longo prazo, contínuo e sistemático em } \\
\text { vários processos paralelos, tanto } \\
\text { intelectualmente } \\
\text { organizacionalmente. A A trantónão } \\
\text { hierárquica da sala de cirurgia é } \\
\text { frequentemente ambígua, protegida por } \\
\text { suas estruturas seguras, mas ainda restrita } \\
\text { por padrões tradicionais. Relações de } \\
\text { confiança e comunicação resoluta dentro } \\
\text { da equipe geram condições favoráveis } \\
\text { para a prevenção de ISC. }\end{array}$ \\
\hline $\begin{array}{l}\text { 11. Implementation of a } \\
\text { multifaceted program to } \\
\text { sustainably improve } \\
\text { appropriate intraoperative } \\
\text { antibiotic redosing. }\end{array}$ & Medline & $\begin{array}{l}\text { American } \\
\text { Journal of } \\
\text { Infection } \\
\text { Control. } \\
2018\end{array}$ & $\begin{array}{l}\text { Avaliar a eficácia da } \\
\text { implementação de } \\
\text { um programa } \\
\text { multifacetado para } \\
\text { melhorar de forma } \\
\text { sustentável a redução } \\
\text { de antibióticos intra- } \\
\text { operatório. }\end{array}$ & $\begin{array}{l}\text { A implementação de uma intervenção } \\
\text { multifacetada melhorou as taxas de } \\
\text { redução de ISC, em conformidade com as } \\
\text { diretrizes de antibióticos profiláticos } \\
\text { intraoperatórios. }\end{array}$ \\
\hline $\begin{array}{l}\text { 12. Comparação das taxas } \\
\text { de infecção cirúrgica após } \\
\text { implantação do checklist } \\
\text { de segurança. }{ }^{19}\end{array}$ & Scielo & $\begin{array}{l}\text { Acta Paul } \\
\text { Enferm. } \\
2018\end{array}$ & $\begin{array}{l}\text { Comparar as taxas de } \\
\text { ISC em cirurgia } \\
\text { limpa, antes e após } \\
\text { implantação do } \\
\text { checklist proposto } \\
\text { pela OMS. }\end{array}$ & $\begin{array}{l}\text { Observou-se redução significativa da taxa } \\
\text { de ISC nas cirurgias limpas, quando } \\
\text { comparados os períodos pré e pós- } \\
\text { implantação do checklist. }\end{array}$ \\
\hline $\begin{array}{l}\text { 13. National Survey of } \\
\text { Operating Room Nurses' } \\
\text { Aseptic Techniques and } \\
\text { Interventions for patient } \\
\text { preparation to reduce }^{20} \\
\text { surgical site infections. }^{20}\end{array}$ & Medline & $\begin{array}{l}\text { Surgical } \\
\text { Infections. } \\
2018\end{array}$ & $\begin{array}{l}\text { Descrever as } \\
\text { intervenções clínicas } \\
\text { diárias que os } \\
\text { enfermeiros suecos } \\
\text { realizaram para } \\
\text { prevenir ISC } \\
\text { seguindo as diretrizes } \\
\text { nacionais. }\end{array}$ & $\begin{array}{l}\text { A padronização das intervenções } \\
\text { preventiva se tornou a principal } \\
\text { prioridade. De modo geral, os enfermeiros } \\
\text { do centro cirúrgico têm alta conformidade } \\
\text { com as diretrizes sobre intervenções para } \\
\text { prevenir o crescimento bacteriano no } \\
\text { paciente cirúrgico. }\end{array}$ \\
\hline $\begin{array}{l}\text { 14. Take the initiative to } \\
\text { reduce surgical site } \\
\text { infections. }^{21}\end{array}$ & Medline & $\begin{array}{c}\text { Nursing. } \\
2018\end{array}$ & $\begin{array}{l}\text { Descrever uma } \\
\text { iniciativa focada na } \\
\text { prevenção de ISC } \\
\text { profundas e suas } \\
\text { potenciais } \\
\text { complicações. }\end{array}$ & $\begin{array}{l}\text { O projeto alcançou uma redução dramática } \\
\text { na taxa de ISC na instituição. A equipe do } \\
\text { centro cirúrgico está orgulhosa com a taxa } \\
\text { de } 0,1 \% \text { em ISC profunda, e continuará } \\
\text { trabalhando em direção a taxa zero. }\end{array}$ \\
\hline $\begin{array}{l}\text { 15. Incidência e fatores de } \\
\text { risco para infecção de } \\
\text { sítio cirúrgico em } \\
\text { cirurgias gerais. }^{22}\end{array}$ & Scielo & $\begin{array}{l}\text { Rev. } \\
\text { Latino- } \\
\text { Am. } \\
\text { Enfermage } \\
\text { m. } \\
2017\end{array}$ & $\begin{array}{l}\text { Estimar a incidência } \\
\text { de ISC em cirurgias } \\
\text { gerais de um hospital } \\
\text { brasileiro de grande } \\
\text { porte, identificando } \\
\text { fatores de risco e } \\
\text { microrganismo } \\
\text { prevalente. }\end{array}$ & $\begin{array}{l}\text { Identificada a incidência de ISC de } 3,4 \% \text {. } \\
\text { Os fatores de risco associados foram: } \\
\text { tempo de internação pré-operatório maior } \\
\text { que } 24 \text { horas; tempo de duração da } \\
\text { cirurgia; potencial de contaminação da } \\
\text { ferida; e índice ASA. O Staphyloccocus } \\
\text { aureus e Escherichia coli foram } \\
\text { identificados. }\end{array}$ \\
\hline $\begin{array}{l}\text { 16. Pré-operatório de } \\
\text { cirurgias potencialmente } \\
\text { contaminadas: fatores de } \\
\text { risco para infecção do } \\
\text { sítio cirúrgico. }^{23}\end{array}$ & $\begin{array}{l}\text { Lilacs } \\
\text { Scielo }\end{array}$ & $\begin{array}{l}\text { Acta Paul } \\
\text { Enferm. } \\
2017\end{array}$ & $\begin{array}{l}\text { Associar fatores de } \\
\text { risco do período pré- } \\
\text { operatório, de } \\
\text { cirurgias } \\
\text { potencialmente } \\
\text { contaminadas } \\
\text { realizadas em } \\
\text { hospital escola da }\end{array}$ & $\begin{array}{l}\text { A ISC no período pós-operatório } \\
\text { hospitalar ocorreu em } 10 \% \text {, e no pós- } \\
\text { operatório domiciliar } 46,7 \% \text {. Os fatores de } \\
\text { risco sexo, idade, doenças de base, } \\
\text { medicações, etilismo e tabagismo foram } \\
\text { significativos para o desenvolvimento } \\
\text { destas infecções. }\end{array}$ \\
\hline
\end{tabular}




\begin{tabular}{|c|c|c|c|c|}
\hline & & & $\begin{array}{l}\text { região Sul do Brasil, } \\
\text { com a ocorrência da } \\
\text { ISC no período pós- } \\
\text { operatório hospitalar } \\
\text { e em domicilio. }\end{array}$ & \\
\hline $\begin{array}{l}\text { 17. Infecção de sítio } \\
\text { cirúrgico pós-alta: } \\
\text { ocorrência e } \\
\text { caracterização de egressos } \\
\text { de cirurgia geral. }{ }^{24}\end{array}$ & Lilacs & $\begin{array}{l}\text { Cogitare } \\
\text { Enferm. } \\
2017\end{array}$ & $\begin{array}{l}\text { Investigar a } \\
\text { ocorrência de ISC e } \\
\text { descrever as } \\
\text { características dos } \\
\text { casos de pacientes } \\
\text { em seguimento pós- } \\
\text { alta de cirurgia geral. }\end{array}$ & $\begin{array}{l}\text { No período foram realizados } 2.772 \\
\text { procedimentos da cirurgia geral e } 2.283 \\
\text { pacientes }(82,28 \%) \text { compareceram ao } \\
\text { acompanhamento pós-alta. Foram } \\
\text { diagnosticados } 85 \text { casos de infecção, uma } \\
\text { incidência média de } 3,7 \% \text { no período. } \\
\text { Verificou-se maior ocorrência de casos de } \\
\text { infecção entre o } 6^{\circ} \text { e } 10^{\circ} \text { dia pós- } \\
\text { operatório. }\end{array}$ \\
\hline $\begin{array}{l}\text { 18. Failure to Redose } \\
\text { Antibiotic Prophylaxis in } \\
\text { Long Surgery Increases } \\
\text { Risk of Surgical Site } \\
\text { Infection. }{ }^{25}\end{array}$ & Medline & $\begin{array}{c}\text { Surgical } \\
\text { infections. } \\
2017\end{array}$ & $\begin{array}{c}\text { Examinar os efeitos } \\
\text { da profilaxia } \\
\text { antibiótica no risco } \\
\text { de ISC. }\end{array}$ & $\begin{array}{l}\text { Os dados demonstram que a falha em } \\
\text { redose o antibiótico profilático durante } \\
\text { operações longas aumenta o risco de ISC. } \\
\text { O fortalecimento de um programa } \\
\text { colaborativo de melhoria da qualidade } \\
\text { cirúrgica pode ajudar a erradicar esse } \\
\text { risco. }\end{array}$ \\
\hline $\begin{array}{l}\text { 19. Prática de profilaxia } \\
\text { antimicrobiana cirúrgica } \\
\text { como fator de segurança } \\
\text { do paciente. }{ }^{26}\end{array}$ & Lilacs & $\begin{array}{l}\text { Surgical } \\
\text { Infections. } \\
2016\end{array}$ & $\begin{array}{l}\text { Identificar a prática } \\
\text { da profilaxia } \\
\text { antimicrobiana } \\
\text { cirúrgica adotada } \\
\text { pelos profissionais } \\
\text { atuantes em centro } \\
\text { cirúrgico. }\end{array}$ & $\begin{array}{l}\text { Constatou-se que em } 81(81 \%) \text { das } \\
\text { cirurgias limpas, potencialmente } \\
\text { contaminadas e contaminadas, a profilaxia } \\
\text { antimicrobiana foi realizada. Entretanto, } \\
\text { na maioria delas }(54 / 66,6 \%) \text { o anti- } \\
\text { microbiano não foi administrado dentro de } \\
\text { uma hora antes da cirurgia. } \\
\text { Adicionalmente, em } 18,1 \% \text { das cirurgias } \\
\text { potencialmente contaminadas e em } 33 \% \\
\text { contaminada, que seu uso é indispensável, } \\
\text { o antimicrobiano não foi administrado. }\end{array}$ \\
\hline
\end{tabular}

\subsection{Infecção de Sitio Cirúrgico}

$\mathrm{Na}$ realidade hospitalar, os procedimentos cirúrgicos são amplamente utilizados e oferecem inúmeros riscos, apesar de todo o avanço em pesquisas e tecnologia ${ }^{14}$. Cerca de um em cada quatro pacientes desenvolve complicações pós-operatórias dentro os quatorze primeiros dias após a alta hospitalar - estima-se que estas complicações advindas da ferida cirúrgica representem $4 \%$ dos custos totais do sistema de saúde ${ }^{2}$.

Ao se cortar a pele durante um procedimento cirúrgico, os microrganismos que residem em camadas mais externas, podem ser transferidas para o local da incisão cirúrgica e causar uma ISC ${ }^{15}$. As feridas cirúrgicas são os tipos de feridas mais comumente tratadas em ambiente de cuidados intensivos, estando associadas a uma variedade de complicações como sangramentos e deiscência ${ }^{2}$. 
Entre os principais patógenos responsáveis pelas ISC estão a Escherichia coli, a Staphy lococcus aureus, Estafilococos coagulase-negativos e Entero coccus spp. A transferência desses patógenos pode se dar de maneira direta ou indireta, pelo toque inadvertido em maçanetas, teclado de computador, carrinhos cirúrgicos de pacientes ou qualquer outro equipamento na sala de cirurgia ${ }^{15}$. A ocorrência deste tipo de infecção representa importante problema de saúde pública, constituindo-se na principal causa de iatrogenia em pacientes submetidos a intervenções invasivas ${ }^{10}$.

As ISC podem se manifestar até 30 dias após a cirurgia, ou em até 90, nos casos em que houver colocação de implantes. Sua classificação se dá de acordo com o grau de acometimento: incisional, superficial profunda ou infecção de órgão e/ou cavidade ${ }^{9,10}$. As graves consequências advindas dessas infecções impõem a necessidade de criação de esforços para sua prevenção, sendo a determinação dos fatores e risco uma das estratégias utilizadas, por permitir a identificação de situações e/ou condições clínicas que predisponham um paciente ao desenvolvimento de infecção ${ }^{26}$.

Caso a infecção se instale, esta pode propiciar grandes encargos socioeconômicos, elevando os custos assistenciais e da morbimortalidade, devido ao aumento do tempo de internação, da antibioticoterapia associada, das cirurgias necessárias à reconstrução do tecido, além do prolongamento do afastamento das atividades laborais e dos familiares do paciente ${ }^{26}$. Quando não tratadas, as infecções de sítio cirúrgico podem causar infecção profunda da ferida, formação de sepses e abscessos, falha na cicatrização da ferida e deiscência e falha do implante, como também impacto em demais aspectos do bem-estar do paciente e em relação à sua recuperação funcional ${ }^{9}$.

São diversos os fatores de risco conhecidos descritos pela literatura, os quais compõem o Índice de Risco de Infecção Cirúrgica do National Nosocomial Infection Surveillance System (NISS), bem como o Índice da American Society of Anesthesiologists 
(ASA), que classifica os pacientes levando em consideração seu quadro clínico e o Potencial de Contaminação da Ferida Operatória $(\mathrm{PCFO})^{22}$.

No Brasil, as ISC já ocupam a terceira posição entre as infecções em serviço de saúde, sendo estimado em $15 \%$ dos encontrados em pacientes hospitalizados, sendo que os fatores associados à infecção da ferida podem estar relacionados ao próprio paciente e à execução da técnica cirúrgica e ambiental onde se realizará o procedimento cirúrgico ${ }^{10}$.

Constituem fatores de risco para as ISC, o tempo de duração da cirurgia; o tempo de internação pré-operatório; o potencial de contaminação da ferida operatória; as doenças préexistentes, como obesidade e diabetes mellitus; e fatores de risco como tabagismo e uso de imunodepressores ${ }^{14}$. Citam-se, ainda, outros fatores como os extremos de idade; aplicação inapropriada da antibiocoprofilaxia; tempo de duração cirúrgica; habilidade técnica da equipe cirúrgica; e fatores associados ao próprio patógeno, como virulência e resistência oferecida aos antimicrobianos ${ }^{24}$.

A falta de conhecimento acerca do risco de resistência culminou no rápido aumento da resistência aos antibióticos ${ }^{17}$. A resistência antimicrobiana contribui de forma significativa para as ISC, onde cerca de 38,7 a 50,9 dos microrganismos cultivados em ISC se mostram resistentes aos antibióticos convencionais - microrganismos resistentes a um ou mais agentes antimicrobianos são chamados de organismos resistentes às múltiplas drogas ${ }^{16}$.

O potencial de contaminação da ferida cirúrgica refere-se ao número de microrganismos presentes no tecido a ser operado, o que representa o risco de contaminação maior na medida em que aumenta o potencial de contaminação ${ }^{26}$ - serve como referência para a classificação das cirurgias ${ }^{19}$. São denominadas cirurgias limpas às realizadas em tecidos estéreis ou passíveis de descontaminação, bem como ausência de processo infeccioso e/ou inflamatório local ou falhas técnicas grosseiras. Observa-se a cicatrização por primeira intenção e a ausência de drenagem ${ }^{19}$. São consideradas cirurgias potencialmente contaminadas 
as realizadas em tecidos colonizados por flora microbiana pouco numerosa ou em tecidos colonizados ausentes de processo inflamatório e infeccioso ou, ainda, com falhas técnicas discretas no intra-operatório. Pode ocorrer penetração no trato respiratório, digestório e urinário sem contaminação significativa. Como exemplos, citam-se as cirurgias das vias biliares (sem estase ou obstrução biliar), cirurgia gástrica e duodenal, colecistectomia, feridas traumáticas limpas, cirurgias cardíacas prolongas (com circulação extracorpórea) e vagotomia com drenagem ${ }^{23}$.

Na presença de maior contaminação ou infecção local, as cirurgias ainda podem ser classificadas como contaminada e infectada. Assim, as cirurgias são classificadas de acordo com as áreas que afetam; como superficial, quando acomete pele e tecido subcutâneo; profundo, quando atinge tecidos moles e profundos; e cavidades de órgãos, quando afetam qualquer estrutura anatômica manipulada durante a intervenção cirúrgica ${ }^{11}$ - sua classificação se dá de acordo com o grau de acometimento: incisional, superficial profunda ou infecção de órgão e/ou cavidade ${ }^{19}$.

Ademais, todos os pacientes cirúrgicos estão em risco de desenvolver ISC ${ }^{15}$. Contudo, ressalta-se que as infecções do sítio cirúrgico apesar de se constituem nos tipos mais comuns são, também, o tipo de infecção hospitalar mais evitável pela prevenção².

\subsection{Enfermagem e as diretrizes para a prevenção da infecção de sítio cirúrgico}

Na década de 1980, no Brasil, foram publicadas as primeiras portarias que priorizavam a prevenção e o controle das infecções hospitalares ${ }^{14}$. A Organização Mundial da Saúde (OMS) preocupada com questões relativas à segurança do paciente e a fim de mitigar eventos adversos associados à assistência, lançou o Desafio Global para a Segurança do Paciente definiu padrões de segurança cirúrgica voltados à prevenção de $\operatorname{ISC}^{26}$.

Destacam-se como recomendações adotadas para a prevenção e controle das ISC as medidas de Precaução Padrão, que devem ser realizadas no contato com todos os pacientes ou 
sempre que houver perigo de contato com sangue e/ou fluidos corporais, independente dos fatores de risco ou doença de base do paciente ${ }^{14}$. A necessidade de precauções adicionais baseia-se na forma como o organismo infeccioso pode ser transmitido - podendo incluir precauções de contato, precauções aerotransportadas e precauções de gotículas ${ }^{26}$.

Entre as Precauções Padrão citam-se a correta higienização das mãos - antes e após os procedimentos; a utilização de luvas para redução de microrganismos; a utilização de aventais, máscaras e proteção facial; a prevenção de acidentes com material biológico; dentre outros. ${ }^{14}$ Com relação à higienização das mãos, trata-se de um procedimento muito importante por proteger não somente o paciente de possíveis microrganismos advindos dos profissionais de saúde, como para proteger os profissionais dos microrganismos do paciente. A higienização adequada das mãos consiste em molhar as mãos em água corrente, preferencialmente água morna, aplicando sabão em todas as superfícies e esfregando por quinze segundos. Ao final do procedimento, enxaguar as mãos e secá-la com uma toalha que servirá, também, para fechar a torneira ${ }^{21}$.

Para os casos em que as mãos não apresentarem sujidades visíveis, a utilização de um antisséptico à base de álcool se apresenta como uma alternativa aceitável. A técnica adequada à higienização das mãos com utilização de produto à base de álcool consiste na aplicação do gel e fricção das mãos até que toda a solução seque - aproximadamente vinte segundos ${ }^{21}$.

O desenvolvimento de ISC pode ser influenciado por fatores relacionados aos procedimentos, que podem ocorrer antes, durante ou após sua realização. Entre os fatores no procedimento pré-operatório, citam-se o banho pré-operatório e a profilaxia antibiótica. $\mathrm{O}$ banho pré-operatório se constitui de uma lavagem de corpo inteiro com sabonete antimicrobiano na noite anterior à cirurgia planejada ${ }^{15}$.

Sobre os antibióticos profiláticos perioperatórios, são capazes de diminuir a taxa de ISC e, por outro lado, caso sua seleção seja feita de forma inadequada, seu ajuste de dose 
inicial seja incorreto, ou ocorra falha na redose; tais fatores podem anular tal benefício e levar ao aumento das taxas de ISC e risco de infecções resistentes aos antibióticos. As diretrizes atuais recomendam que a seleção dos antibióticos seja apropriada para cada tipo de procedimento específico, sendo o tempo recomendado para sua administração de uma hora antes da incisão cirúrgica, ou de duas horas, caso se faça uso de vancomicina ou fluoroquinolona ${ }^{18}$.

Quando administrado de forma correta, os antibióticos perioperatórios são capazes de diminuir a taxa de ISC, no entanto, a seleção e/ou dose inadequada podem anular tal benefício e aumentar das taxas de infecção e dos custos ligados à saúde ${ }^{18}$. Essas recomendações baseiam-se na farmacocinética e eficácia dos antibióticos, para manter as concentrações plasmáticas adequadas de antibióticos a cirurgia ${ }^{25}$.

Além dessa problemática, não é incomum o uso rotineiro de produtos que, apesar de caros, se mostram inadequados para o tratamento da ferida cirúrgica. Geralmente, isso se dá devido à abundância de produtos no mercado voltados ao tratamento de feridas e as agressivas estratégias de marketing mesmo diante das ausências de evidências científicas ${ }^{2}$.

\subsection{Enfermagem no contexto da infecção da ferida cirúrgica}

Embora internacionalmente existam divergências em relação à profissão responsável por preparar o paciente para o procedimento cirúrgico, em geral esta tarefa é realizada pela equipe de enfermagem. Dentre as funções recomendadas está a degermação da pele do paciente, manutenção de sua temperatura corporal, cuidados com os instrumentais cirúrgicos, circulação de sala operatória e auxiliar a equipe cirúrgica de forma geral ${ }^{20}$.

A segurança do paciente se constitui, na perspectiva da enfermagem, um componente essencial para a assistência de enfermagem de qualidade, que não se constitui somente em uma parte do que fazer, mas diz respeito ao comprometimento destes profissionais com seu Código de Ética Profissional - para a segurança, competência e cuidado ético ${ }^{26}$. 
Estudo de Pagamisse e col. ${ }^{13}$ apontou o enfermeiro como o profissional fundamental para compor a equipe na realização de ações de vigilância de ISC durante e após a internação de pacientes. No que diz respeito às ações de vigilância na internação, destacaram-se sua função na busca ativa e análise da cultura microbiológica. Entre as vantagens da vigilância ativa de possíveis casos de ISC estão a prevenção de danos emocionais e físicos, a readmissão e a redução dos custos relativos ao tratamento ${ }^{13}$. Com relação à redução dos custos, ressalta-se que as ISC são consideradas as mais onerosas entre as infecções associadas aos cuidados de saúde, devido ao aumento do tempo de internação de três a quatro dias por ocorrência ${ }^{15}$.

Além do acompanhamento ativo dos casos no período de internação, a vigilância pósalta se constitui em fator primordial em que diversos métodos são empregados, como o contato via telefone; a carta ou e-mail, e a busca em prontuários farmacêuticos que indiquem a utilização de antibióticos. ${ }^{13}$

O reconhecimento e diagnóstico precoces da ISC são fundamentais no tratamento imediato e faz parte do processo de vigilância da infecção da ferida. A fim de desempenhar esse papel de maneira eficaz, é necessário que os enfermeiros compreendam como reconhecer com precisão a infecção da ferida, como também seu papel na vigilância 9 .

É possível reduzir as taxas de ISC utilizando-se diversas estratégias, entre as quais estão inclusas as precauções de controle de infecção ${ }^{9,10}$. Além do acompanhamento ativo dos casos durante o período de internação, a vigilância pós-alta também se constitui em um fator primordial, tendo em vista que estatisticamente cerca de $12 \%$ a $84 \%$ das ISC são diagnosticadas após o paciente deixar o hospital ${ }^{24}$.

Durante todo o período perioperatório, cabe à equipe de enfermagem proceder com os cuidados específicos para cada tipo de procedimento cirúrgico, realizando o controle das infecções, buscando ferramentas para a redução das taxas prevalentes das ISC, bem como dos fatores de risco. Fazem parte do período perioperatório os estágios pré-operatório, 
intraoperatório e pós-operatório, que implicam no desempenho interdependente da equipe de enfermagem e cirúrgica ${ }^{15}$.

O período pré-operatório é o intervalo de tempo que se inicia no momento de reconhecimento da necessidade de uma cirurgia e finaliza com a chegada do paciente ao centro cirúrgico. Nessa fase é importante que o enfermeiro utilize instrumentos para avaliar o risco de ISC e elabore intervenções educativas voltadas ao autocuidado do paciente ${ }^{12}$. Recomenda-se criar e manter o campo cirúrgico estéril com a utilização de lençóis esterilizados e realizar a preparação da pele com antimicrobianos, a fim de fornecer uma área esterilizada para a execução da cirurgia ${ }^{15}$.

Durante o período intraoperatório, é importante a manutenção do controle glicêmico, limitação das transfusões sanguíneas e restrição do suprimento intravenoso intraoperatório. No caso de cirurgias iguais ou superiores a três horas, deve-se aplicar corretamente uma segunda dose de profilaxia antimicrobiana ${ }^{11}$.

O enfermeiro atua no campo operatório na realização de sondagens vesicais de demora e colabora com a supervisão da adesão às técnicas assépticas, de modo a assegurar que todas as recomendações sejam cumpridas. Igualmente, a cobertura da ferida operatória e a identificação de possíveis lesões de pele decorrentes do período intraoperatório são procedimentos de extrema importância ${ }^{12}$. Recomenda-se para o fechamento de feridas cirúrgicas limpas a combinação de sutura com gaze de cobertura primária - encontram-se disponíveis no mercado grampos, adesivos e outros dispositivos mais avançados. Para os casos das feridas que não se podem aproximar as bordas, como no caso de deiscência, têm sido cada vez mais utilizada à terapia de curativo a vácuo que apresentam ótimos resultados ${ }^{12}$.

Estudo de Souza e Serrano ${ }^{14}$ demonstrou ser possível evitar grande parte dos eventos adversos através da adoção de ações de prevenção de ISC, garantindo a segurança do paciente em todo o período perioperatório. Como ações prioritárias no pós-operatório, destacam-se as 
trocas diárias de curativos cirúrgicos com técnica asséptica e a paramentação adequada (uso de luvas, máscara, óculos, capote e touca) ${ }^{14}$.

Destaca-se que o período de internação é proporcional ao risco de ISC, tendo em vista que a ausência de Sala de Recuperação pós-anestésica conduz os pacientes em pós-operatório imediato ao repouso nas enfermarias compartilhadas. A segregação inapropriada pode se constituir num fator prejudicial que aumenta as chances dos pacientes serem colonizados por flora bacteriana hospitalar ${ }^{10}$.

Contudo, a fim de reduzir a ocorrência de complicação pós-cirúrgica, o enfermeiro precisa avaliar os fatores predisponentes e de riscos à infecção, a fim de adotar medidas preventivas e educacionais para todos os sujeitos envolvidos, por meio de um processo de sensibilização coletiva ${ }^{14}$.

\section{CONSIDERAÇÕES FINAIS}

As ISC são as complicações cirúrgicas mais comuns e podem se desenvolver na pele superficial ou nas camadas mais profundas dos tecidos. O enfermeiro se constitui no profissional de referência para realizar as ações de vigilância das infecções durante o período de internação e no pós-alta.

As diretrizes atuais reforçam a importância das medidas de precauções em relação às infecções, como precauções padrão, de contato, por aerotransportadas e por gotículas; e as suas relações com o bem-estar e segurança do paciente e do profissional de saúde. Reforça a correta higienização das mãos, a utilização de insumos para prevenção de acidentes com materiais biológicos, além da utilização de antibióticos profiláticos perioperatórios.

A equipe de enfermagem que atua no centro cirúrgico é responsável pela implementação de princípios de higiene e assepsia a fim de prevenir e limitar a propagação de infecções, desde a orientação e preparo do paciente no período pré-operatório, na aplicação de 
medidas de segurança no transoperatório, e com os cuidados de enfermagem no período pósoperatório.

A prevenção da infecção cirúrgica requer uma abordagem multifatorial. O enfermeiro perioperatório fornece os cuidados necessários aos seus pacientes a fim de minimizar os riscos de infecção, uma vez que é considerada uma das mais temidas complicações decorrentes da intervenção cirúrgica - podem ser um episódio grave, com elevado custo financeiro e associado ao aumento da morbidade e mortalidade.

\section{REFERÊNCIAS}

1 Baptiste J, Cruz EDA, Alpendre FT, Rocha DJM, Brandão MB, Maziero ECS. Prevalence and avoidability of surgical adverse events in a teaching hospital in Brazil. Rev. Latino-Am. Enfermagem. 2019;27:e2939:1-9. doi: doi.org/10.1590/15188345.2939 .3171

2 Gillespie BM, Walker RM, McInnes E, Moore Z, Eskes AM, Connor TO, et al. Preoperative and postoperative recommendations to surgical wound care interventions: a systematic meta-review of Cochrane reviews. International Journal of Nursing Studies. 2020;102(103486):1-14. doi: doi.org/10.1016/j.ijnurstu.202.103486

3 Sousa FO, Silva SJ, Silva AM, Silva MR, Santos AS, Silva LM, et al. Prevenção das infecções no período Perioperatório: Participação da equipe de enfermagem. Brazilian Journal of Health Review. 2021;4(3):11813-11823. doi: doi.org/10.34119/bjhrv4n3-168

4 Hernández-Romero L, Romero-Quechol GM, Zamudio-Costeño L, Olea-Martínez M. Competencia clínica del personal de enfermería para la prevención de infección del sitio quirúrgico. Rev Enferm Inst Mex Seguro Soc. 2019;27(1):4-13. doi: biblio-996118. 
5 Telemberg VB, Amante LN, Martins T, Telemberg VC, Pinho FM, Silva R. Adverse events in a hospital surgical unit: a decriptive study. Rev. Sobecc. 2016; 21(3):146-153. doi: doi.org/10.5327/Z1414-4425201600030005

6 Souza, ISB, Santana AC, D’Alfonso Júnior G. A ocorrência de infecção do sítio cirúrgico: um estudo de revisão. Rev Med Minas Gerais. 2018;28(Supl5):eS280521:168-175. http://www.dx.doi.org/10.5935/2238-3182.20180133

7 Martins T, Amante LN, Vicente C, Sousa GM, Caurio EP, Guanilo MEE, et al. Intervenções de enfermagem para reduzir infecção do sítio cirúrgico em cirurgias potencialmente contaminadas: revisão integrativa. Estima, Braz. J. Enterostomal Ther. 2020;18(e20): doi: doi.org/10.30886/estima.v18.848_PT

8 Galvão TF, Pansani TSA, Harrard D. Principais itens para relatar revisões sistemáticas e meta-análises: a recomendação prisma. Epidemiol Serv Saúde. 2015;24(2):335-342. doi: doi.org/10.5123/S1679-49742015000200017

9 Copanitsanou P, Santy-Tomlinson J. The nurses' role in the diagnosis and surveillance of orthopaedic surgical site infections. International Journal of Orthopaedic and Trauma Nursing. 2021;41:1-5. doi: doi.org/10.1016/j.ijotn.2020.100818

10 Silva EM, Silva RKS, Carvalho SB, Façanha DMA, Carvalho REFL, Pereira FGF. Fatores de risco para infecção de sítio cirúrgico em cirurgias traumato-ortopédicas. Revista Cuidarte. 2021;12(2):e1292:1-14. doi: doi.org/10.15649/cuidarte.1292

11 Cantú EIH, Dávila SPE, Silva AKSR. Eficacia de un modelo de prevención de infección de sitio quirúrgico en un hospital de segundo nivel de atención. Index Enferm. 2020; 29(1):1-2. Doi: doi.org/10.4321/S1132-12962020000100003

12 Gomes ET, Poveda VB, Püschel VAA. Ações de enfermagem podem prevenir deiscência em ferida operatória? Rev Sobecc. 2020;25(2):114-119. doi: doi.org/10.5327/Z14144425202000020008 
13 Pagamisse AF, Tanner J, Poveda VB. Post-discharge surveillance of surgical site infections in teaching hospitals in Brazil. Rev Esc Enferm USP. 2020;54:e03542:1-7. doi: doi.org/10.1590/s1980-220x2018038203542

14 Souza KV, Serrano SQ. Saberes dos enfermeiros sobre prevenção de infecções do sítio cirúrgico. Rev. Sobecc 2020;25(1):11-16. doi: doi.org/10.5327/Z14144425202000010003

15 Bashaw MA, Keister KJ. Perioperative strategies for surgical site infection prevention. AORN Journal. 2019;109(1):68-78. doi: doi.org/10.1002/aorn.12451

16 Link T. Guideline implementation: transmission-based precautions. AORN 2019; 110(6):637-649. doi: doi.org/10.1002/aorn.12867

17 Qvistgaard M, Lovebo J, Almerud-Österberg S. Intraoperative prevention of surgical site infections as experienced by operating room nurses. International Journal of Qualitative Studies on Health and Well-being. 2019,14(1):1-7. doi: doi.org/10.1080/17482631.2019.1632109

18 O'Sullivan CT, Rogers WK, Ackman M, Goto M, PharmD BMH. Implementation of a multifaceted program to sustainably improve appropriate intraoperative antibiotic redosing. American Journal of Infection Control. 2018;47(1):74-77. doi: doi.org/10.1016/j.ajic.2018.06.007

19 Prates CG, Stadñik CMB, Bagatini A, Caregnato RCA, Moura GMSS. Comparação das taxas de infecção cirúrgica após implantação do checklist de segurança. Acta Paul Enferm. 2018;31(2):116-22. doi: doi.org/10.1590/1982-0194201800018

20 Wistrand C, Falk-Brynhildsen K, Nilsson U. National Survey of Operating Room Nurses' aseptic techniques and interventions for patient preparation to reduce surgical site infections. Surgical Infections. 2018;19(4):1-8. doi: doi.org/10.1089/sur.2017.286 
21 Woodruff J, Hohler SE. Take the initiative to reduce surgical site infections. Nursing. 2018;48(12):62-64. doi: doi.org/10.1097/01.NURSE.0000546454.56122.93

22 Carvalho RLR, Campos CC, Franco LMC, Rocha AM, Ercole FF. Incidência e fatores de risco para infecção de sítio cirúrgico em cirurgias gerais. Rev. Latino-Am. Enfermagem. 2017;25:e2848. doi: doi.org/10.1590/1518-8345.1502.2848

23 Martins T, Amante LN, Virtuoso JF, Girondi JBR, Nascimento ERP, Nascimento KC. Pré-operatório de cirurgias potencialmente contaminadas: fatores de risco para infecção do sítio cirúrgico. Acta Paul Enferm. 2017;30(1):16-24. doi: doi.org/10.1590/19820194201700004

24 Reis RG, Rodrigues MCS. Infecção de sítio cirúrgico pós-alta: ocorrência e caracterização de egressos de cirurgia geral. Cogitare Enferm. 2017;4(22):51678:1-10. doi: doi.org/10.5380/ce.v22i4.51678

25 Kasatpibal N, Whitney JD, Dellinger EP, Nair BG, Pikes KC. Failure to redose antibiotic prophylaxis in long surgery increases risk of surgical site infection. Surgical Infections. 2017;1-11. doi: doi.org/10.1093/ofid/ofw172.1151

26 Tostes, MFP, Maran E, Raimundo LS, Mai LD. Prática de profilaxia antimicrobiana cirúrgica como fator de segurança do paciente. Surgical Infections. 2016;21(1):13-21. doi: doi.org/10.5327/Z1414-4425201600010003 